\title{
Ferramentas de Análise Estatística e Correlação para Sistemas de Recuperação da Informação
}

\author{
Khaíck Oliveira Brito ${ }^{1}$; Rodrigo Tripodi Calumby ${ }^{2}$ \\ 1. Bolsista PIBITI/CNPq, Graduando em Engenharia de Computação, UEFS, e-mail: khaickbrito@gmail.com \\ 2. Orientador, Departamento de Ciências Exatas, UEFS, e-mail: rtcalumby@uefs.br
}

PALAVRAS-CHAVE: Recuperação de informação ; Eficácia; Análise estatística

\section{INTRODUÇÃO}

Atualmente, para efetuar o comparativo de sistemas de recuperação da informação (RI) usando medidas de eficácia, pesquisadores/desenvolvedores necessitam utilizar um conjunto de ferramentas para mensurar eficácia, realizar análise estatística, fazer análise de correlação para diferentes cenários e construir modelos visuais para apresentação dos resultados. Em especial, para garantir o rigor científico na análise comparativa de eficácia de diferentes métodos, é necessária a utilização de métodos para determinação da significância estatística considerando a execução dos métodos em múltiplas bases de dados e consultas. De modo geral, estas são tarefas trabalhosas dado que as ferramentas utilizadas em geral consomem e geram dados em diferentes formatos e possuem um conjunto limitado de funcionalidades. Neste trabalho, foi realizada a integração de funcionalidades de análise de significância estatística e correlação AnalyzIR, ferramenta que tem sido desenvolvida na UEFS e que visa disponibilizar ao usuário um ambiente integrado de análise de eficácia de sistema de recuperação de informação

\section{MATERIAL E MÉTODOS}

Novos recursos foram adicionados à ferramenta, como os testes de Mann-Whitney U, Correlação de Spearman, Correlação de Pearson, Coeficiente de Similaridade de Jaccard e que foram aprimorados, como Wilcoxon's Signed Rank Test e Teste t de Student. Os testes de significância estatística formulam duas hipóteses, nula e alternativa, que serão consideradas para concluir acerca das amostragens as quais o teste será aplicado, como por exemplo avaliar a existência de uma diferença significativa entre as médias dessas amostras.

Os testes de Wilcoxon e Mann-Whitney $U$ podem ser aplicados para se comparar duas amostragens relacionadas ou emparelhadas visando verificar diferenças significativas, caso existam, entre os comportamentos dessas amostragens, podendo concluir se há chance de elas pertencerem à mesma população ou não. Ambos computam a diferença entre os valores emparelhados, a magnitude dessa diferença, em seguida ordenam essas diferenças e definem postos sinalizados. Por fim, aplica-se a fórmula estatística do teste em questão, encontrando um valor a ser comparado com o tabelado considerando o grau de liberdade e nível de significância escolhidos. Caso o valor encontrado seja superior ao tabelado, é indicado se rejeitar a hipótese nula de que as amostragens se assemelham ou suas médias são estatisticamente equivalentes.

O cálculo do valor $\mathrm{t}$ de Student se faz de maneira específica mediante a igualdade ou não da variância e da igualdade ou não entre os tamanhos das amostragens. que será comparado posteriormente aos valores encontrado na tabela de valores críticos de $t$, a partir de um grau de liberdade e um valor de confiança. $O$ coeficiente de correlação de Jaccard é uma estatística usada para comparar conjuntos finitos e calcular um índice para a similaridade entre eles. $\mathrm{O}$ valor encontrado utilizando operações entre os conjuntos a serem comparados, fica inserido num intervalo $[0,1]$, em 
que quanto maior o coeficiente mais alta a similaridade. $\mathrm{O}$ coeficiente de correlação de Pearson busca avaliar a existência de uma relação linear entre as variáveis apresentadas nas amostras. Através do cômputo de valores de variância e covariância, o teste de Pearson gera um valor $p$ que indica o grau da correlação encontrado no intervalo [ -1 , 1], em que valores próximos de 1 expressam uma correlação direta entre as variáveis analisadas e -1 para uma correlação inversa e 0 para uma não dependência entre elas. $\mathrm{O}$ teste de correlação de ordem de posto de Spearman, também como em Pearson, procura encontrar e apresentar o tipo de relação existente entre as variáveis contínuas ou ordinais apresentadas a partir de valores de covariância e desvio padrão.

Para efetuar o teste de Spearman devidamente na ferramenta, foi necessário desenvolver e aplicar um método de adaptação para rankings que não compartilharem de todos os elementos entre si, ou seja, que não tenha totalidade de intersecção nos elementos dos rankings, estimando o posto de um elemento não presente em um ranking, mas presente no outro, sendo mais distante o posto atribuído ao elemento ausente que se encontra mais próximo do topo do ranking ao qual ele pertence, de modo a permitir o cômputo do coeficiente. $\mathrm{O}$ método proposto se dá da seguinte forma:

1) Forma-se um conjunto com a união dos elementos dos rankings $\mathrm{A}$ e $\mathrm{B}$, sendo $\mathrm{A}$ e B conjuntos com tamanhos iguais.

2) Criam-se dois novos vetores, $\mathrm{A} 1$ e $\mathrm{B} 1$, correspondentes à $\mathrm{A}$ e $\mathrm{B}$. Para cada elemento dessa união:

3) Verifica-se se ele existe em ambos os vetores originais A e B

4) Caso exista em algum deles, o valor da sua posição no seu vetor de origem. será guardado no vetor correspondente ao vetor original em que foi encontrado

5) Caso somente exista em um dos dois rankings originais, o posto atribuído a esse elemento no vetor correspondente ao ranking ao qual o elemento não faz parte será calculado pela Equação (1), onde T corresponde ao tamanho do ranking original e $\mathrm{P}$ é a posição ocupada pelo elemento no ranking original.

$$
\text { Posto }=2 \mathrm{~T}-\mathrm{P}
$$

A Figura 1 demonstra a aplicação do método de adaptação em questão onde $A$ e B são vetores de tamanhos iguais porém com alguns elementos iguais (A, B e C) e outros diferentes ( $\mathrm{D}$ e $\mathrm{E})$.

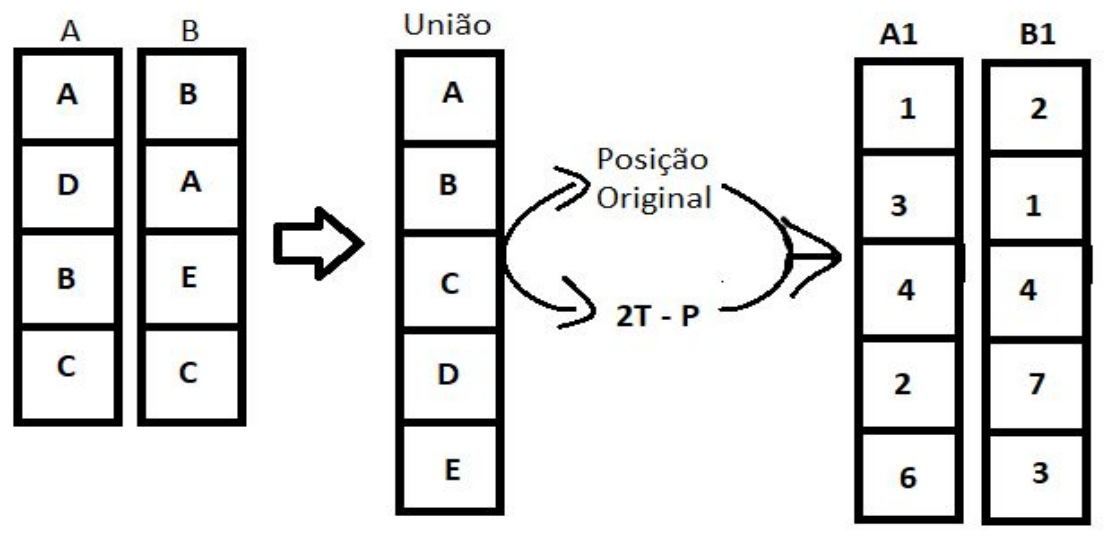

Figura 1: Exemplo de adaptação de rankings. 
Tratando-se da aplicação desses testes em relação à ferramenta e à análise de sistemas de RI, os parâmetros necessários para se efetuar devidamente os testes são:

1) Testes de Wilcoxon e Mann-Whitney $U$ : Escolha de dois sistemas a serem avaliados, um valor para o grau de confiança (e.g., 0.05), uma medida de avaliação, um valor de profundidade para os rankings e uma ou mais consultas.

2) Teste t de Student: Escolha de dois sistemas a serem avaliados, um valor para o grau de confiança (e.g., 0.05), uma medida de avaliação, um valor de profundidade para os rankings e uma ou mais consultas.

3) Teste de Spearman e coeficiente de Jaccard: Escolha de um ou mais sistemas, uma ou mais consultas e um valor de profundidade.

4) Teste de Pearson: Escolha de dois sistemas a serem avaliados, uma medida de avaliação, um valor de profundidade para os rankings e uma ou mais consultas.

\section{RESULTADOS}

A interface para os testes de Wilcoxon e Mann Whitney $U$, exibida na Figura 2A, apresenta os campos necessários para sua execução, bem como sua região de resultados. Existe a possibilidade de três versões para o teste de Wilcoxon, Apache Commons Math (ACM) [1], Java Statistical Classes (JSC) [2] e Mackenzie [3], e duas para Mann Whitney $U$, ACM e JSC, que podem ser escolhidas na interface apresentada.

As interfaces para os testes $t$ de Student e correlação de Pearson se assemelham à apresentada na Figura 2A. A tela de configuração dos teste de Jaccard e Spearman pode ser vista na Figura $2 \mathrm{~B}$.
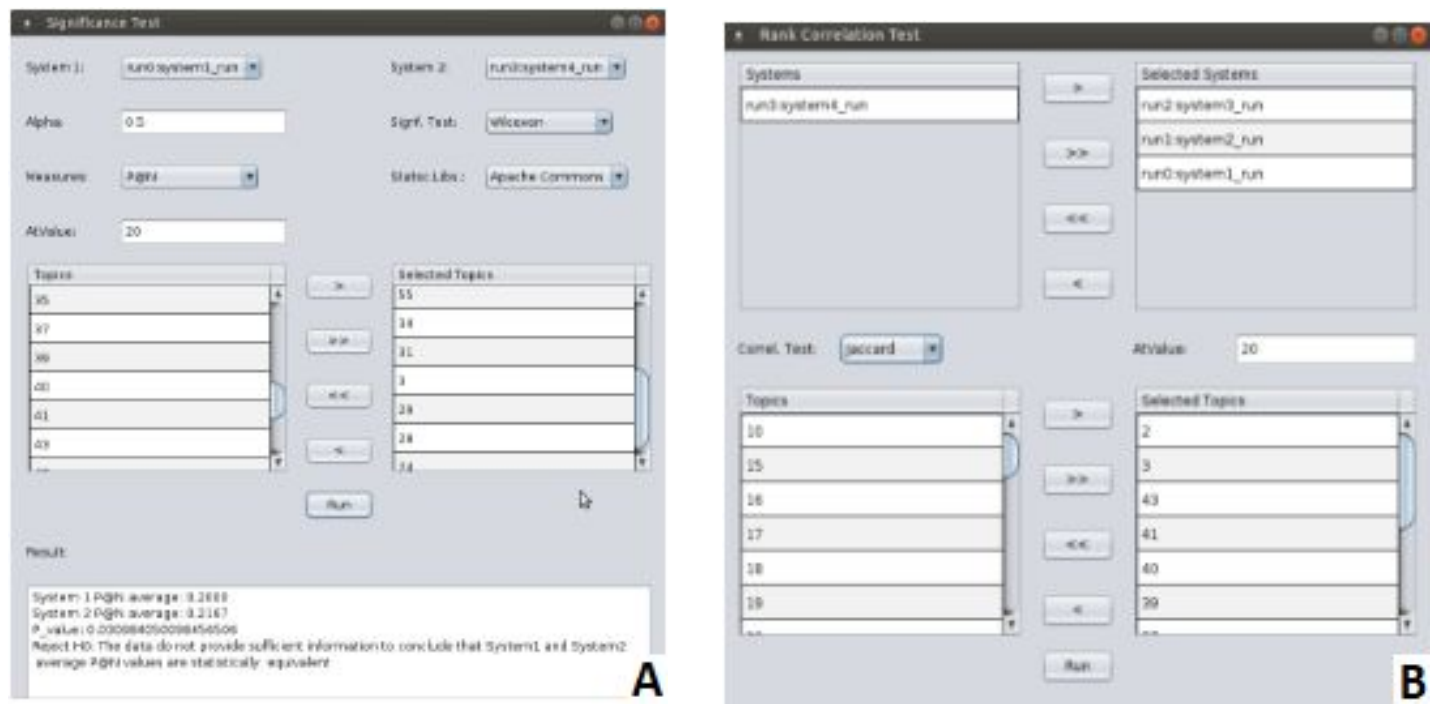

Figura 2: Telas de configuração A - Interface para os testes de Wilcoxon e Mann Whitney $U$; B - Interface para os testes de Jaccard e Spearman.

Além dos testes, foi disponibilizada também na ferramenta a possibilidade de visualização de resultados de alguns testes por meio de mapa de calor, apresentado na Figura 3, o qual permite edições em títulos, legendas e escala de cores. É possível realizar a exportação desse mapa de calor em formatos png e jpg. 




Figura 3: Exemplo de mapa de calor gerado e exportado.

\section{CONSIDERAÇÕES FINAIS}

Ao término desse projeto de iniciação tecnológica, pôde-se contemplar os resultados obtidos satisfatoriamente, incluindo o aprimoramento da ferramenta AnalyzIR, que se deu pela incorporação do módulo estatístico desenvolvido nesse projeto, o que permitirá aos pesquisadores que fizerem uso da ferramenta efetuarem testes com bibliotecas conceituadas e suporte a múltiplos sistemas, o que permite um maior rigor para conclusões científicas, visualizações de resultados de forma mais intuitiva através de mapas de calor com legendas e cores customizáveis junto à exportação de resultados e tipos diferentes de arquivos, para se adequar às diferentes necessidades.

\section{REFERÊNCIAS}

[1] COMMONS MATH: THE APACHE COMMONS MATHEMATICS LIBRARY. Disponível em: <http://commons.apache.org/proper/commons-math/> Acesso em: 15 ago. 2018.

[2] CLASS WILCOXON SIGNED RANK. Scott MacKenzie. Disponível em: $<$ http://www.yorku.ca/mack/HCIbook/stats/WilcoxonSignedRank.html/> Acesso em: 15 ago. 2018.

[3] JAVA STATISTICAL CLASS. Disponível em: <www.jsc.nildram.co.uk> Acesso em: 15 out. 2017. 